\title{
An Analysis of LSA Relaxation Oscillations in GaAs
}

\author{
Jeppesen, Palle; Jeppsson, B
}

Published in:

1st European Microwave Conference

Link to article, DOI:

10.1109/EUMA.1969.331840

Publication date:

1969

Document Version

Publisher's PDF, also known as Version of record

Link back to DTU Orbit

Citation (APA):

Jeppesen, P., \& Jeppsson, B. (1969). An Analysis of LSA Relaxation Oscillations in GaAs. In 1st European Microwave Conference (pp. 216-218). IEEE. https://doi.org/10.1109/EUMA.1969.331840

\section{General rights}

Copyright and moral rights for the publications made accessible in the public portal are retained by the authors and/or other copyright owners and it is a condition of accessing publications that users recognise and abide by the legal requirements associated with these rights.

- Users may download and print one copy of any publication from the public portal for the purpose of private study or research.

- You may not further distribute the material or use it for any profit-making activity or commercial gain

- You may freely distribute the URL identifying the publication in the public portal

If you believe that this document breaches copyright please contact us providing details, and we will remove access to the work immediately and investigate your claim. 
AN ANALYSIS OF LSA RELAXATION OSCILLATIONS IN GaAs.

P. Jeppesen and B. Jeppsson

It has been shown $|1|$ that many times oversized n-GaAs diodes when operated in a high impedance waveguide past structure oscillated in a LSA relaxation mode. It is the purpose of this paper to present a simple analysis of the LSA relaxation mode and to show a new circuit suitable for operation of epitaxial diodes in this mode.

Fig. 1 shows the $X$-band waveguide iris circuit, consisting of two shorted high impedance parallel plate transmission lines, foreshortened to resonate the device capacitance. In front of the iris is shown two ridge waveguide quarter wavelength transformers for optimization of the diode load impedance. Using epitaxial GaAs, $64 \mu \mathrm{m}$ thick and doped to $1.8 \times 10^{15} \mathrm{~cm}^{-3}, 45 \mathrm{~W}$ peak power was obtained in this circuit at $10 \mathrm{GHz}$ with an efficiency of $10 \%$. In a similar $\mathrm{K}_{\mathrm{A}}$-band circuit the same material yielded $25 \mathrm{~W}$ peak power at 31 $\mathrm{GHz}$ with $5 \%$ efficiency. In high duty cycle experiments $75 \mathrm{~mW}$ average power at $10 \mathrm{GHz}$ and $45 \mathrm{~mW}$ at $31 \mathrm{GHz}$ was obtained.

The transmission line equivalent diagram of the waveguide iris circuit is shown in Fig. 2a, along with the circuit parameters. The total diode load impedance is represented by an inductance in parallel with a resistan$\mathrm{ce}, \mathrm{Fig} .2 \mathrm{~b}$. Both the inductance and the resistance are frequency dependent, their calculated values normallized to the diode low-field impedance shown in Fig. 3.

Using the transmission line circuit of Fig. 2a time-domain computer simulations, including internal diode space charge dynamics, resulted in the steady state diode voltage waveshape shown in Fig. 4. The voltage is normalized to the threshold voltage, $\mathrm{V}_{\mathrm{TH}}$ •

Design criteria and understanding of the ISA relaxation mode is gained from a simple analysis of the oscillator shown in Fig. 5. The LSA diode is represented by a piecewise linear current voltage characteristic and a total parallel capacitance $C_{t}=g(f) C_{0}$, where $C_{O}$ is the dielectric capacitance of the active layer and $g(f) \AA^{\prime}$ slightly ${ }^{\circ}$ frequency and voltage dependent factor taking into account the electronic contribution to the total capacitance. The transmission line in Fig. 5 represents the two shorted parallel plate transmission lines forming the iris shown in Fig. 1. This line is foreshortened to resonate the total diode capacitance at the fundamental frequency $f$, when the following well-known condition is satisfied:

$$
\ell \frac{2 \pi f}{c}=\tan ^{-1}\left[\frac{Y_{0}}{g(f) C_{0} 2 \pi f}\right]=\tan ^{-1}\left[\frac{e \mu_{0}}{2 \pi \varepsilon g(f)} \frac{Y_{0}}{G_{0}} \frac{n_{0}}{f}\right]
$$

Here $c$ is the velocity of light, e the electronic charge, $\mu_{0}$ the low field mobility, $\varepsilon$ the permittivity of GaAs, $n_{0}$ the doping level and $G_{0}$ the low $\mathrm{n}_{0}=1.8 \times 10^{15} \mathrm{~cm}^{-3}, \mathrm{Y}_{0}=0.01 \Omega^{-1}, \mathrm{G}_{0}=0.40 \Omega^{-1}$ and $\mathrm{g}(\mathrm{f}) \simeq 4$ the transmission line is short enough to be approximated by the inductance

$$
L=\frac{1}{Y_{0}} \frac{\ell}{c}
$$

The same approximation in equation (1) also gives

This work was done at Cornell University and Cayuga Associates, Ithaca,N.Y. P. Beppesen is now with the Techn. University of Denmark, Lingby, Denmark. B. Jeppsson is now with the Royal Institute of Techn., Stockholm, Sweden. 


$$
f=\frac{e \mu_{0} c}{4 \pi^{2} E B(f)} \frac{Y_{0}}{G_{0}} \frac{n_{0}}{f} \frac{I}{l}
$$

In agreement with experiments equation (3) shows the dependence of the oscillation frequency on the admittance ratio, the doping to frequency ratio and the length of the transmission line.

The voltage waveshape shown in Fig. 4 can be understood by estimating the time constants involved below ard above threshold. Below threshold the device voltage rises approximately accorking to

$$
V(t)=V_{B}\left[1-\exp \left(-\frac{t}{\tau_{L}}\right)\right]
$$

where the inductive time constant $\tau_{L}=G_{L} L$. From equations ( 3 ) and (4) the fraction, $t_{s} / T$, of the period spend below threshold is given by

$$
\frac{t_{S}}{T}=\frac{e \mu_{0}}{4 \pi^{2} \varepsilon_{G}(f)} \frac{n_{0}}{f} \ln \left(\frac{V_{B}}{V_{B}-V_{T H}}\right)
$$

When reaching $V_{T \text { the }}$ the device voltage will rise very fast because of the negative differential conductance, $G_{1}$. The capacitive time constant for this region of the waveshape is given by

$$
{ }^{\tau} \mathrm{C}=\frac{C_{t}}{G_{I}-Y_{0}-G_{L}} \ll \tau_{L}
$$

The same time constant is applicable when the device voltage decays through the negative conductance region. Further analysis has shown that the portion above threshold only slightly depends on bias voltage and is shorter than the subthreshold portion for moderate bias levels. Therefore, the observed voltage tuneability of the LSA relaxation mode is understood from equation (4).

The fast rise of the device voltage to nearly full amplitude in the first cycle after applying the bias pulse prevents domain formation and thus eliminates fatal avalanching in the starting of long LSA diodes and allows series operation of several such diodes.

In conclusion, for the LSA relaxation oscillator design criteria have been established based on a simple analysis, which is in good agreement with experimental results and with complete computer simulations.

REFERENCE

(1) B. Jeppsson and P. Jeppesen, "A high power LSA relaxation oscillator", Proc. IEEE (Letters), vol. 57, June 1969.

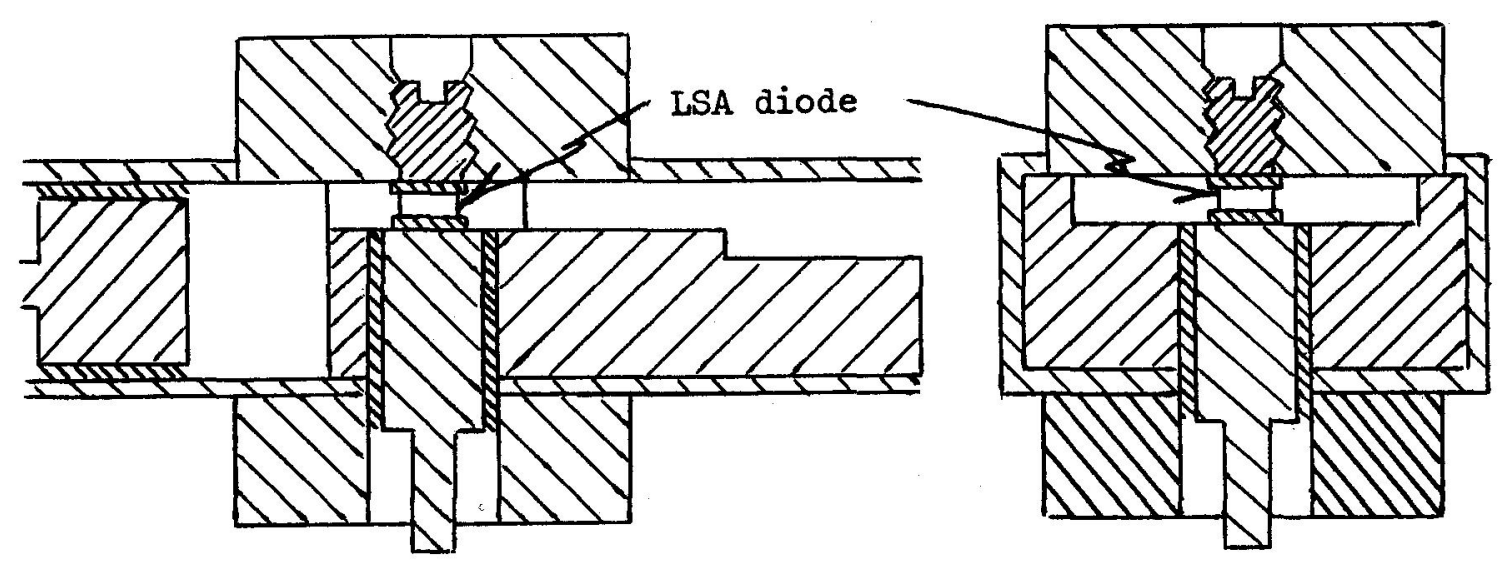

Fig. $I \mathrm{X}$-band waveguide iris circuit 
a)

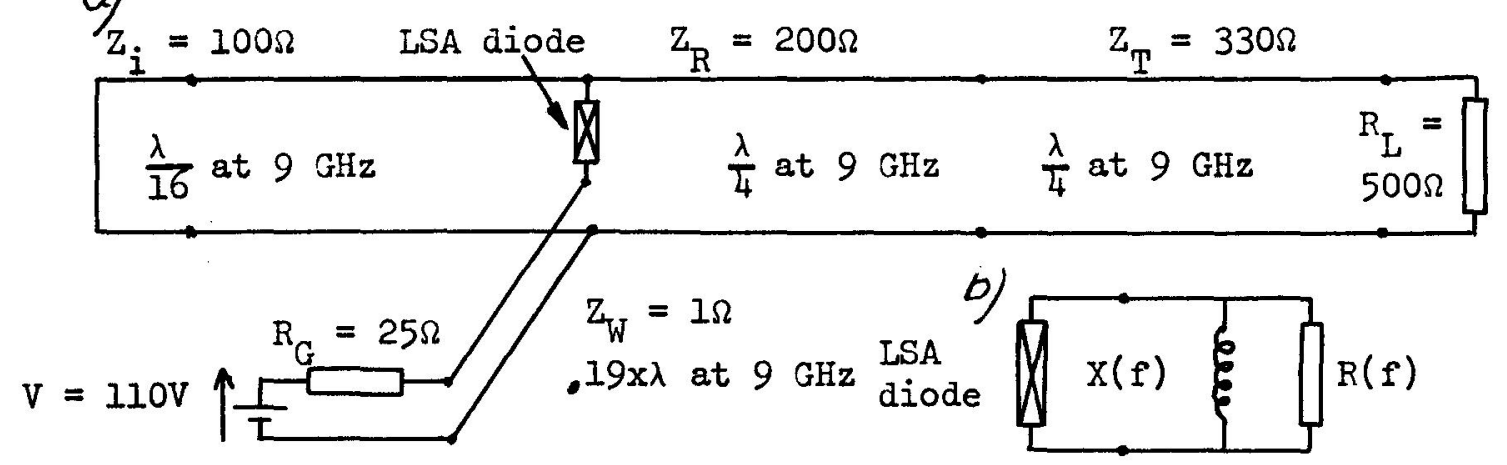

Fig. 2a) Transmission line equivalent diagram

$2 \mathrm{~b}$ ) Representation of total diode load impedance

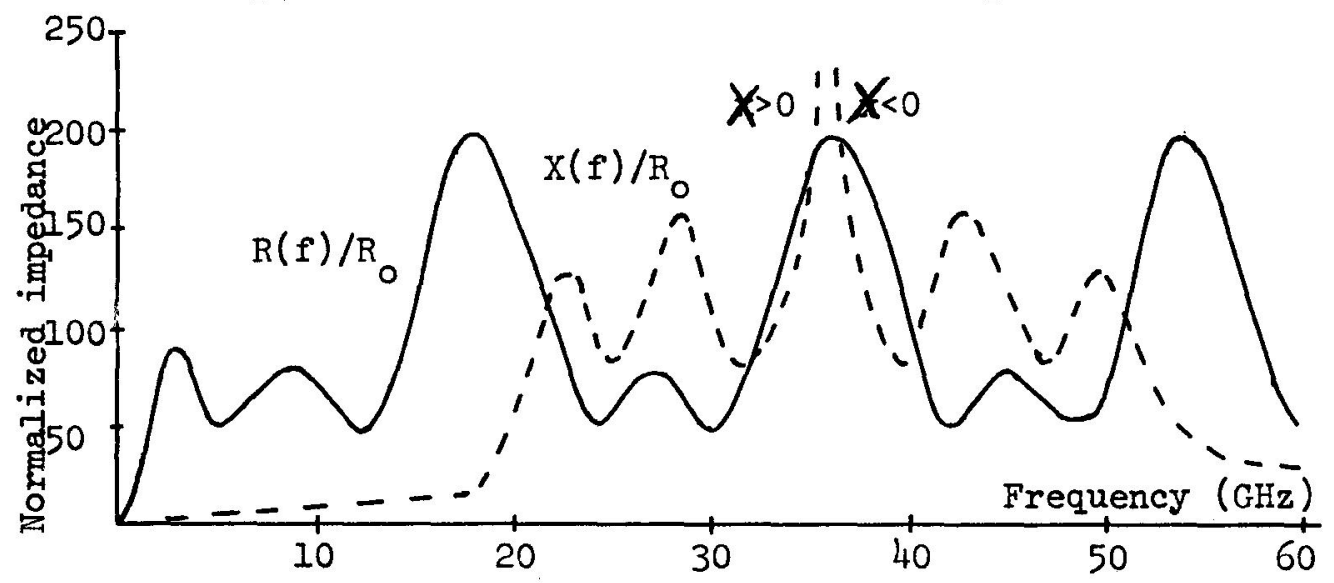

Fig. 3 Frequency dependence of total diode load impedance

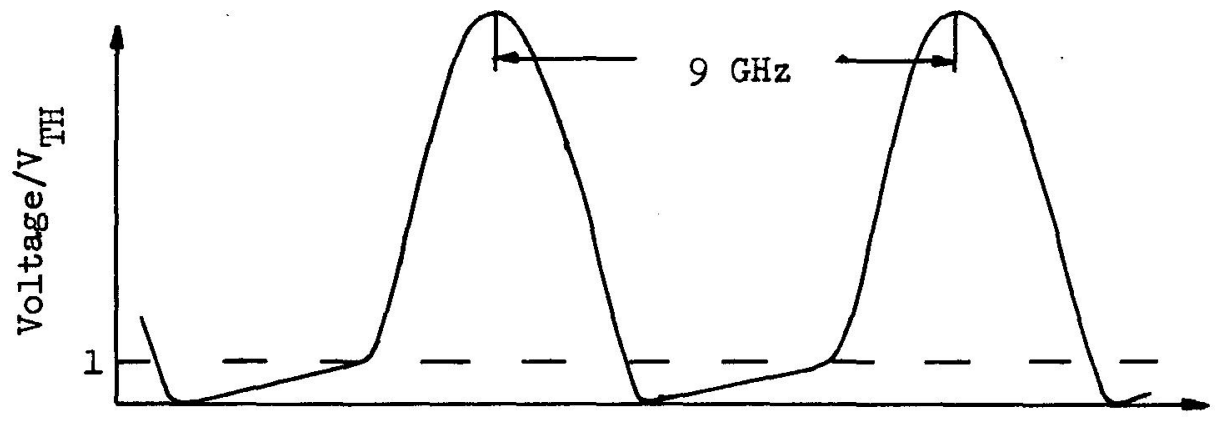

Time

Fig. 4 Device voltage waveshape from computer simulation
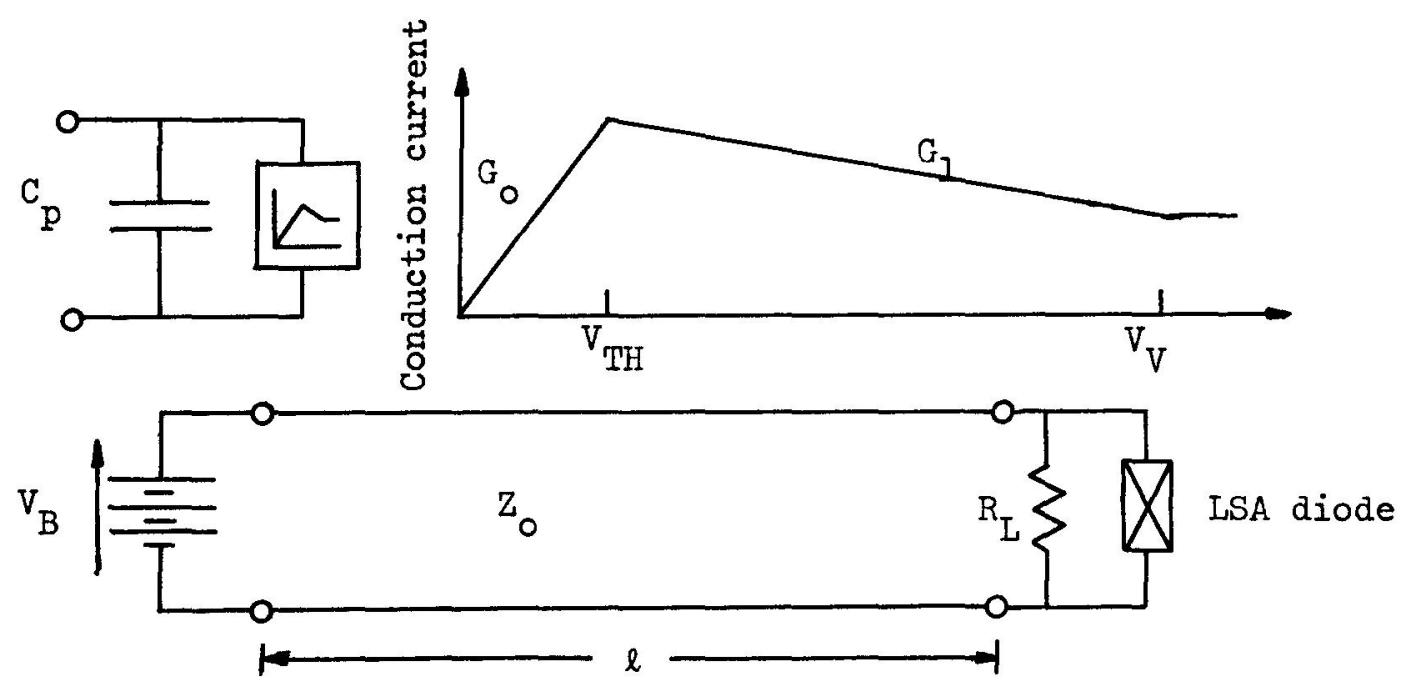

Fig. 5 Simple LSA relaxation oscillator 